\title{
Exploring the impacts of McService on customers' loyalty: An emerging market's perspective
}

\author{
Kyuho Lee, kyuho.lee@sonoma.edu \\ Mahmood Khan, khan@vt.edu \\ Inhyuck "Steve" Ha , iha@email.wcu.edu \\ Jae-Youn Ko, jyko@khu.ac.kr
}

\begin{abstract}
Developing a foreing country has become crucial among U.S. fast-food restaurant operators who have been challenged by increasing U.S. consumers' preferences on healthy menu items, the domestic market's saturation and a fierce competition (Patton, 2014). Surpringly, the U.S. fast chains' penetration in Asian markets is notable. For example, the number of McDonald's in Japan, and China in 2015 were 2,975 and about 2,000 respectively which have increased from 604 and 3 in 1987 respectively (Pingali, 2006; McDonald's China; McDonald's Japan). Not only giant fast-food chains such as McDonald's and YUM corporation but also medium sized burger chains such as Shake Shack burger have started developing Asian markets to continue to grow. Recently, Shake and Shack, a New-York based fast-food burger chain, has announced to enter Korean market in 2016 ( Lee \& Kim, 2016).
\end{abstract}

Increasing middle-class consumers, preferences for western lifestyle, and urbanization among emegering Asian countries have fueled Asian consumers to eat more Western fastfood (Pingali, 2006; Watson, 2000). Nonetheless, developing an Asian market is risky due to high cultural, geographical, political and language differences between U.S. and the Asian market. One of the most challenging issues that U.S. fast-food chains have encountered in developing Asian markets is Asian consumers' different expectations and motivations on dining at a U.S. fast-food restaurant ( Lee \& Ulgado, 1997, Witkowski \& Ma, 2003). More importantly, a consumers' dietary preference and habits is closely related to a local culture a consumer is affiliated with (Vignali, 2001).

Although a plethora of studies have developed to delve into underlying motivations and perceptions of consumers fast-food consumption among American consumers there are very few studies published with respect to perspectives on fast-food consumption from an emerging Asian market's consumers. To the best of our knowledge, no study exists that investigate the relationships between the key attribtutes of service quality and intent to return in the context of McDonad's service with perspective the emerging Asian market.

The purpose of this study is to explore the key service attributes of McDonald's that affect the loyalty of the emgering Asian market's consumers. This study adopts Korean consumers as a sample of the study to better understand an emerging market's consumers 
perspective on McDonald's service. Korea has become one of important international markets for U.S. fast-food chains. Currently, McDonald's Korea has operated more than 409 July 2015 since it opened its first store in Seoul in 1988 and it is one of the firm's eight high growth international markets out of over 100 countries where the firm has entered (Park, 2015). The value of McDonald's brand equity is $\$ 39,809$ million which makes the firm as top 9 global brand and it is the only restaurant brand ranked in top 10 global brand (Interbrand.com).

This study is designed to answer the following research questions:

- What are the major service attributes that affect Korean consumers' loyalty on McDonald's Korea?

- What is the impacts of the key quality attributes on Korean consumers' loyalty of McDonald's?

\section{References}

Interbrand (2016) The best 100 brands. [Online] Available from http://interbrand.com/best-brands/best-global-brands/2015/

Lee, M., \& Ulgado, F. M. (1997) Consumer evaluations of fast-food services: a crossnational comparison. Journal of Services Marketing. 11 (1). p. 39-52.

Lee, J., \& Kim, S. (2016). Shack Shake Burger in Korea. [Online] Available from http://news.chosun.com/site/data/html_dir/2016/07/27/2016072700935.html

Patton, L. (2014). Have we reached peak burger, [Online] Available from http://www.bloomberg.com/bw/articles/2014-09-04/fast-food-chains-growth-in-udot-s-dot-may-have-peaked

Park, S. (2015). McDonald's and Burger have expanded in Korea. [Online] Available from http://www.g-enews.com/ko kr/news/article/news_all/201507261053029421108_1/article.html

Pingali, P. (2006) Westernization of Asian diets and the transformation of food systems: Implications for research and policy. Food Policy. 32. p. 281-298.

Vignali, C. (2001). McDonald's: "think global, act local"- the marketing mix. British Food Journal, 103 (2). p. 97-111.

Watson, J. L. (2000). China’s Big Mac attack. Foreign Affairs, 79 (3), p. 120-134.

Witkowski, T. H.,\& Ma, Y. (2003). Cross-cultural influences on brand identity impressions: KFC in China and the United States. Asia Pacific Journal of Marketing and Logstics. 15 (1/2). p. 74-88.

Keywords: McDonald's, McService, Fast-food, Emerging Market 
Relevance to Marketing Educators, Researchers and Practitioners: This paper helps students better understand international service strategy.

\section{Author Information:}

Kyuho Lee is an Assistant Professor of Marketing at Sonoma State University.

Mahmood Ko is a Professor of Hospitality Management at Virginia Tech.

Inhyuck "Steve" Ha is a Professor of Economics at Western Carolina University.

Jae-Youn Ko is a Professor of Hospitality Management at KyungHee University in Korea.

TRACK: Services Marketing 